Research Article

\title{
Combined Treatment of Non-Small-Cell Lung Cancer Using Shenyi Capsule and Platinum-Based Chemotherapy: A Meta-Analysis and Systematic Review
}

\author{
Yong Xu, ${ }^{1}$ Wenpan Peng, ${ }^{1}$ Di Han, ${ }^{1}$ Zhichao Wang, ${ }^{1}$ Cheng Gu, ${ }^{1}$ Fanchao Feng, ${ }^{1,2}$ \\ Xianmei Zhou $\mathbb{B}^{1},{ }^{1,2}$ and Qi Wu $\mathbb{B}^{3}$ \\ ${ }^{1}$ Affiliated Hospital of Nanjing University of Chinese Medicine, Nanjing 210029, China \\ ${ }^{2}$ Department of Respiratory Medicine, Jiangsu Province Hospital of Chinese Medicine, Nanjing 210029, China \\ ${ }^{3}$ Department of Physiology, Xuzhou Medical University, Xuzhou 221009, China
}

Correspondence should be addressed to Xianmei Zhou; zhouxianmeijs@aliyun.com and Qi Wu; wqak123@126.com

Received 21 July 2020; Accepted 20 September 2020; Published 13 October 2020

Academic Editor: Yukihiro Shoyama

Copyright ( $\odot 2020$ Yong Xu et al. This is an open access article distributed under the Creative Commons Attribution License, which permits unrestricted use, distribution, and reproduction in any medium, provided the original work is properly cited.

Background. The efficacy and safety of combined treatment of non-small-cell lung cancer (NSCLC) using Shenyi capsules and platinum-based chemotherapy were comprehensively evaluated. Methods. A computer-based search was used to identify reports on clinical randomized controlled trials (RCTs) on this combined treatment for NSCLC from the PubMed, Embase, Cochrane Library, China National Knowledge Infrastructure (CNKI), VIP, China Biomedical (CBM), and Wanfang Data electronic databases. The databases were searched from their start to February 2020. The quality of the included studies was evaluated and then crosschecked by two independent evaluators. A meta-analysis was conducted using RevMan5.3. Results. A total of 27 RCTs involving 2,663 patients were included in the meta-analysis, including 1,380 and 1,283 patients in the treatment and control groups, respectively. The results of the meta-analysis showed that, compared to platinum-based chemotherapy alone, the 1-year survival rate (relative risk $(\mathrm{RR})=1.27,95 \%$ confidence interval $(\mathrm{CI})[1.10,1.47], P<0.01)$, 2 -year survival rate $(\mathrm{RR}=1.35,95 \% \mathrm{CI}$ $[1.10,1.65], P<0.01)$, objective tumour remission rate $(\mathrm{RR}=1.52,95 \% \mathrm{CI}[1.35,1.71], P<0.01)$, and body $\mathrm{CD} 4^{+} / \mathrm{CD} 8^{+} \mathrm{ratio}$ (standardized mean difference $(\mathrm{SMD})=0.12,95 \% \mathrm{CI}[0.07,0.17], P<0.01)$ were increased for the combined treatment of NSCLC using Shenyi capsules and platinum-based chemotherapy; moreover, quality of life was also improved $(\mathrm{RR}=2.09,95 \% \mathrm{CI}[1.75$, $2.50], P<0.01)$ and it reduced leukocyte toxicity $(\mathrm{RR}=0.49,95 \% \mathrm{CI}[0.39,0.63], P<0.01)$, haemoglobin toxicity $(\mathrm{RR}=0.48,95 \%$ $\mathrm{CI}[0.28,0.81], P<0.01)$, platelet toxicity $(\mathrm{RR}=0.44,95 \% \mathrm{CI}[0.28,0.70], P<0.01)$, vomiting reaction $(\mathrm{RR}=0.60,95 \% \mathrm{CI}[0.45$, 0.78], $P<0.01$ ), and serum vascular endothelial growth factor level (SMD $=-63.67,95 \% \mathrm{CI}[-67.59,-59.75], P<0.01)$. Conclusions. The treatment of NSCLC using Shenyi capsules together with routine platinum-based chemotherapy could enhance short- and long-term efficacy, improve patient quality of life, alleviate toxicity and side-effects of platinum-based chemotherapeutic drugs, boost body immune function, and inhibit tumour neovascularisation. These findings require further validation in large-sample, high-quality RCTs.

\section{Introduction}

Lung cancer, a malignant tumour with the highest incidence worldwide, can be divided into small-cell and non-small-cell lung cancer (NSCLC) [1]. NSCLC comprises approximately $85 \%$ of lung cancer cases. The five-year survival rate of NSCLC patients is usually less than $5 \%$ because patients are usually diagnosed in advanced cancer stages and have missed their optimal chances for operation [2]. Combined chemotherapy based on platinum-based drugs is a standard treatment strategy for advanced NSCLC and is recommended by many domestic and international authorities [3]. Although chemotherapy can significantly reduce tumour volume, it is usually accompanied by severe toxicity and side-effects, with side-effects frequently seen in the haematological and digestive systems [4]. Therefore, a current 
research hotspot is the identification of drugs to enhance the efficacy and simultaneously reduce the toxicity and sideeffects of chemotherapy [5].

In recent years, Chinese medicines have been widely used for supplementary treatment of lung cancer to significantly enhance treatment efficacy and improve patient quality of life. Shenyi capsules are the first listed inhibitors of tumour neovascularisation in China. Actually, the Shenyi capsule contains a single compound, Ginsenoside Rg3 (10 mg/capsule), a monomer of ginsenoside extracted from ginseng. Modern pharmacological studies showed that Rg3 antagonised the formation of tumour neovascularisation, inhibited tumour proliferation and metastasis, induced tumour apoptosis, and increased the radiochemotherapeutic sensitivity of tumour cells [6].

Increasing numbers of RCTs have confirmed the increased efficacy and decreased the toxicity of the combination treatment of NSCLC using Shenyi capsules and platinum-based drugs. However, most of these RCTs have small sample sizes and methodological problems. Therefore, the resulting conclusions have limited reference value. Although a study evaluated the efficacy and safety of the combined treatment for NSCLC in 2018, the quality of the included studies was poor and only five publications were included; furthermore, relatively fewer outcome indexes were involved [7]. Therefore, it is necessary to collect data from domestic and international RCTs on combined treatments of NSCLC using Shenyi capsules and platinumbased chemotherapy and to complete and update the clinical trials to provide current data-based evidence for the clinical application of Shenyi capsules. We report an updated and extended meta-analysis with detailed outcomes for efficacy and adverse events (Figure 1).

\section{Materials and Methods}

2.1. Literature Search Strategy. Studies on Shenyi capsules, NSCLC, and chemotherapy were identified by searching the China National Knowledge Infrastructure (CNKI), VIP, Wanfang Data, Chinese Biomedical (CBM), PubMed, Embase, and Cochrane Library electronic databases. Studies were searched from the start of the corresponding database to February 2020. The search terms included the English words "Shenyi capsule" and ("non-small cell lung cancer" [MeSH] or "Lung Carcinoma," "Non-Small-Cell" [MeSH], or "Non-Small-Cell Lung Carcinoma" [MeSH] or "Carcinoma, Non-Small Cell Lung" [MeSH] or "NSCLC") and "Chemotherapy" $[\mathrm{MeSH}]$ and corresponding Chinese words.

2.2. Inclusion Criteria. Inclusion criteria were (1) studies concerning clinical RCTs, (2) NSCLC diagnosis confirmed by cytological and pathological tests, and (3) a treatment group administered both Shenyi capsules and platinumbased drugs and a control group administered only platinum-based drugs. (4) The outcome should include at least one of the following indicators: (1) tumour objective remission rate; (2) survival rate; (3) KPS; (4) leukocyte toxicity;
(5) haemoglobin toxicity; (6) platelet toxicity; (7) vomiting; (8) immune function; (9) serum VEGF. The data should have sufficient details to ensure the calculation of the risk ratios and its $95 \%$ CIs for each outcome.

2.3. Exclusion Criteria. The criteria for exclusion were as follows: (1) non-RCTs; (2) repeated academic articles or conference papers or duplication of periodical articles and academic dissertation; (3) inconsistent baseline study object data; (4) treatment group not administered a combined treatment of Shenyi capsules and platinum-based chemotherapy drug and lack of platinum-based chemotherapeutic drug administration in the control group.

2.4. Outcome Measures. Main outcome indices of efficacy were short- and long-term efficacy. The long-term efficacy was assessed by 1- and 2-year survival rates, and the shortterm efficacy was assessed by using the judgement criteria for solid tumours from the World Health Organisation (WHO) [8], i.e., efficacy $=$ complete remission $(\mathrm{CR})+$ partial remission. Quality of life was determined using the Karnofsky Performance Scale (KPS) scores. An increase in KPS by more than 10 points indicated improvement, whereas a reduction by more than 10 points indicated degradation. An increase or a reduction of fewer than 10 points between pre- and post-treatment suggested stabilisation. The $\mathrm{CD}^{+} / \mathrm{CD}^{+}$ ratio in T cells of peripheral blood lymphocytes and serum vascular endothelial growth factor (VEGF) levels were assessed as immune and biochemical indicators. Adverse reactions were classified according to the toxicity classification standards of the WHO and divided into grades 0-IV. Grade II-IV toxicities were considered adverse reactions. Secondary outcome indices of efficacy were leukocyte and platelet toxicities in the digestive tract, as well as vomiting.

2.5. Data Extraction and Quality Assessment. The studies were independently compiled, extracted, and then crosschecked by two evaluators. Any divergence was resolved through discussion or by a third researcher. Data including the title, author, date of publication, data source, general information of the study objects, baseline data of the patient, preventative measures, and outcome index were extracted.

The methodological quality of the included studies was evaluated according to the bias risk assessment method recommended by the Cochrane Assistant Network. Seven variables including randomisation scheme, concealed grouping, double-blinding of patients and doctors, blinded assessment of the results, incomplete result data, selectively reported results, and other biases were evaluated to determine the study biases and reliability of the results.

2.6. Statistical Analysis. RevMan5.3 was used for data analysis. Binary variables were analysed based on the relative risk (RR) and continuous variables by mean difference. If the combined data did not have significant heterogeneity $\left(P \geq 0.10, I^{2} \leq 50 \%\right)$, a fixed-effect model was used. If the heterogeneity was significant $\left(P \leq 0.10, I^{2} \geq 50 \%\right)$, a random- 

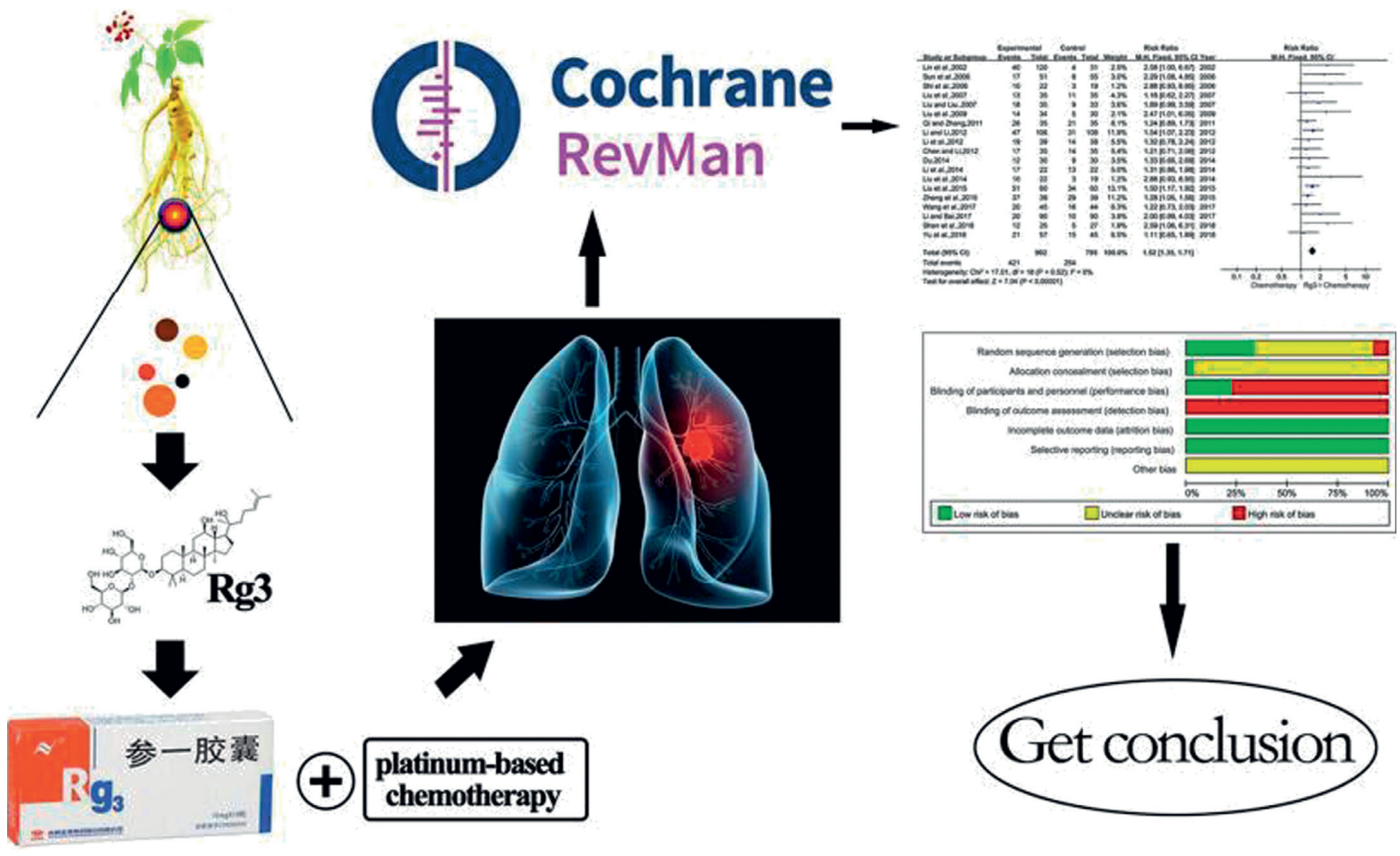

Figure 1: Work flow of the present study.

effect model was used. Forest and funnel plots were used to assess publication bias.

\section{Results}

3.1. Study Identification. A total of 261 studies were retrieved. After duplication removal; title, abstract, and fulltext review; and consideration of the inclusion and exclusion criteria, 27 reports of RCTs involving 2,663 patients were included. A detailed flowchart that presented the process of selection is shown in Figure 2.

3.2. Characteristics of Included Studies. Among the studies included in the present meta-analysis, 12 administered navelbine plus cis-platinum chemotherapy, four administered taxol plus cis-platinum chemotherapy, 13 administered gemcitabine plus cis-platinum chemotherapy, three administered pemetrexed plus carboplatin chemotherapy, two administered pemetrexed plus cis-platinum chemotherapy, and one administered etoposide plus cis-platinum chemotherapy. The Shenyi capsules were administered orally. Among the 27 studies, seven did not include the KPS or PS scores, two did not indicate the neoplasm stage, and 18 studies included patients with KPS scores $>60$ (Table 1).

3.3. Methodological Bias of the Included Studies. Quality assessment of the included studies. All 27 studies included in the present meta-analysis were conducted in China. Among them, nine studies used random number tables and were considered low-risk; 16 studies mentioned the word random but did not describe the randomisation method and the methods could not be confirmed by telephone or e-mail and, thus, were evaluated as unclear. Two studies used incorrect random sequence generation methods and were evaluated as high-risk. One study mentioned allocation concealment and was evaluated as low-risk. It was impossible to determine if allocation concealment was used in 26 studies; thus, they were evaluated as unclear. Six studies mentioned doubleblinded methods and were evaluated as low-risk, while the 21 studies that did not mention double-blinding were evaluated as high-risk. None of the 27 studies mentioned patient dropout and were evaluated as low-risk. The source of bias of these 27 studies could not be determined; thus, they were evaluated as unclear (Figure 3).

\subsection{Outcome Measures}

\subsubsection{Long-Term Efficacy}

(1) One-Year Survival Rate. Seven studies [12,19,23,28-30,34] involving 455 patients compared 1-year survival rates between the treatment $(n=234)$ and control $(n=221)$ groups. The heterogeneity test showed $P=0.03$ and $I^{2}=56 \%$; therefore, a fixed-effect model was used. As shown in Figure 4, the 1-year survival rate was higher in the treatment group than in the control group $(\mathrm{RR}=1.27,95 \% \mathrm{CI}[1.10,1.47], P<0.01)$.

(2) Two-Year Survival Rate. Six studies [12,19,28-30,34] involving 378 patients compared the 2-year survival rates between the treatment $(n=195)$ and control $(n=183)$ groups. Heterogeneity tests showed $P=0.005$ and $I^{2}=71 \%$; therefore, a fixed-effect model was used. As shown in Figure 5, the 2-year survival rate was higher in the treatment 


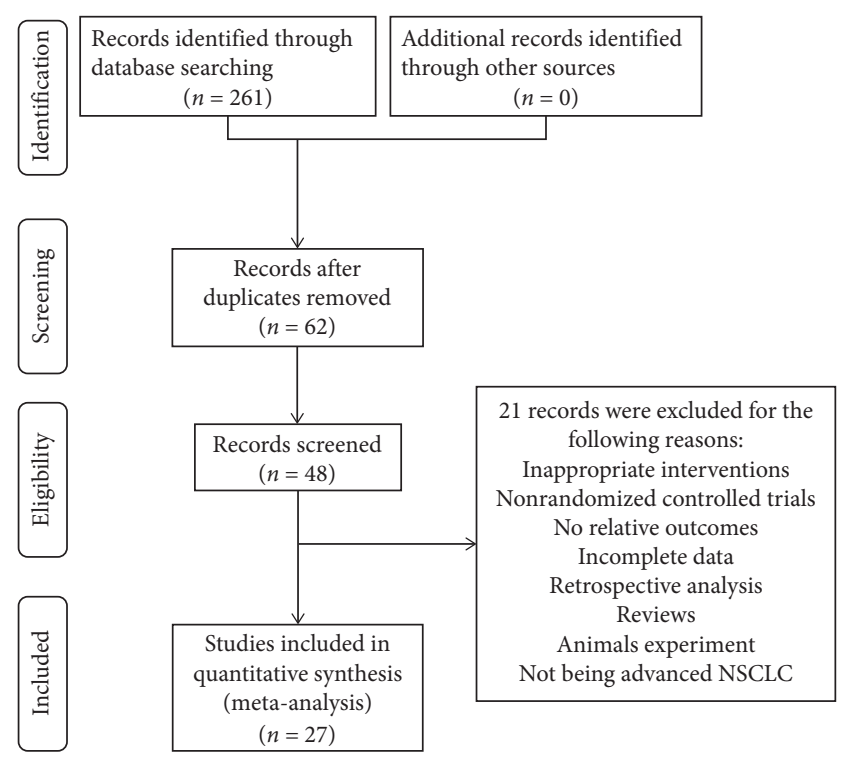

FIGURE 2: Literature retrieval and screening process.

group than in the control group $(\mathrm{RR}=1.35,95 \% \mathrm{CI}[1.10$, 1.65], $P<0.01)$.

3.4.2. Short-Term Efficacy. Nineteen studies [10, 12-14, 16, 18-24, 27, 29, 31-35] involving 1,697 patients compared tumour objective remission rates between the treatment $(n=902)$ and control $(n=795)$ groups. Heterogeneity tests showed $P=0.52$ and $I^{2}=0$; therefore, a fixed-effect model was used. As shown in Figure 6, the short-term efficacy was significantly higher in the treatment group than in the control group $(\mathrm{RR}=1.52,95 \% \mathrm{CI}[1.35,1.71], P<0.01)$.

3.4.3. Performance Status. Twelve studies $[10,13,15,21$, 23-27, 31, 32, 35] involving 1,007 patients compared KPS scores between treatment $(n=557)$ and control $(n=450)$ groups. The heterogeneity test showed $P=0.02$ and $I^{2}=50 \%$; therefore, a fixed-effect model was used. As shown in Figure 7, the quality of life was more improved in the treatment group than in the control group $(\mathrm{RR}=2.09,95 \%$ CI $[1.75,2.50], P<0.01)$.

\subsubsection{Toxicity and Side-Effects}

(1) Leukocyte Toxicity. Thirteen studies $[9,10,14,19,20,23$, $24,26,29-31,33,34]$ involving 1,337 patients compared the degree of reduction in leukocyte counts between the treatment $(n=672)$ and control $(n=665)$ groups. The heterogeneity test showed $P=0.08$ and $I^{2}=38 \%$; therefore, a fixed-effect model was used. As shown in Figure 8, the number of cases with more than two grades of reduction in leukocyte count was lesser in the treatment group than in the control group $(\mathrm{RR}=0.49,95 \% \mathrm{CI}[0.39,0.63], P<0.01)$.

(2) Haemoglobin Toxicity. Nine studies [9, 10, 19, 23, 24, 29, $31,33,34]$ involving 983 patients compared the degree of reduction in haemoglobin in the treatment $(n=494)$ and control $(n=489)$ groups. The heterogeneity tests showed $P=$
0.52 and $I^{2}=0$; therefore, a fixed-effect model was used. As shown in Figure 9, the number of cases with more than two grades of reduction in haemoglobin was lesser in the treatment group than in the control group $(\mathrm{RR}=0.48,95 \%$ CI $[0.28,0.81], P<0.01)$.

(3) Platelet Toxicity. Ten studies [9, 10, 14, 19, 20, 24, 29, 31, $33,34]$ involving 1,130 patients compared the degree of platelet reduction between the treatment $(n=567)$ and control $(n=563)$ groups. The heterogeneity test showed $P=$ 0.42 and $I^{2}=2 \%$; therefore, a fixed-effect model was used. As shown in Figure 10, the number of cases with more than two grades of reduction in platelet count was lesser in the treatment group than in the control group $(R R=0.44,95 \%$ CI $[0.28,0.70], P<0.01)$.

(4) Vomiting. Twelve studies [10, 13, 14, 19, 20, 23-25, 29-31, 34] involving 983 patients compared vomiting between the treatment $(n=506)$ and control $(n=477)$ groups. The heterogeneity test showed $P=0.93$ and $I^{2}=0$; therefore, a fixedeffect model was used. As shown in Figure 11, the number of cases with vomiting reaction above grade II was lesser in the treatment group than in the control group $(R R=0.60,95 \%$ CI $[0.45,0.78], P<0.01)$.

(5) Immune Function. Eight studies [10, 17, 22, 26, 31, 32, 35] involving 767 patients compared the $\mathrm{CD}^{+} / \mathrm{CD}^{+}$ratio of T cells between the treatment $(n=434)$ and control $(n=333)$ groups. The heterogeneity test showed $P=0.52$ and $I^{2}=0$; therefore, a fixed-effect model was used. As shown in Figure 12 , the number of cases with reduced $\mathrm{CD} 4^{+} / \mathrm{CD} 8^{+}$ratio was lesser in the treatment group than in the control group (standardized mean difference $(\mathrm{SMD})=0.12,95 \%$ CI $[0.07$, 0.17], $P<0.01)$.

(6) Serum VEGF Levels. Four studies $[11,15,25,26]$ involving 312 patients compared serum VEGF levels between treatment $(n=157)$ and control $(n=155)$ groups. Heterogeneity test showed $P=0.001$ and $I^{2}=82 \%$; therefore, a random-effects model was used. As shown in Figure 13, the number of cases with reduced serum VEFG level was significantly lower in the treatment group than in the control group (SMD $=-63.67,95 \% \mathrm{CI}[-67.59,-59.75], P<0.01)$.

3.5. Analysis of Publication Bias. The short-term efficacy and quality of life reported in the included studies were subjected to funnel plot analysis (Figure 14). As shown in the scatter diagram, the top part and middle part of the $95 \%$ CI as well as the left and right sides are symmetrical, showing a normal distribution, implying a lack of publication bias.

\section{Discussion}

The incidence and death rates of lung cancer rank first among malignant tumours [36]. In 2018, GLOBOCAN estimated 2.09 million new cases ( $11.6 \%$ of total cancer cases) and 1.76 million deaths (18.4\% of total cancer deaths). About $85 \%$ of lung cancer patients are diagnosed with NSCLC [37]. 
TABLE 1: Baseline characteristics of included studies.

\begin{tabular}{|c|c|c|c|c|c|c|}
\hline \multirow{2}{*}{ Study } & \multirow{2}{*}{$N(\mathrm{~T} / \mathrm{C})$} & \multirow{2}{*}{ Physical } & \multirow{2}{*}{ Stage } & \multicolumn{2}{|l|}{ Interventions } & \multirow{2}{*}{ Outcomes } \\
\hline & & & & $\mathrm{T}$ & $\mathrm{C}$ & \\
\hline Zhang et al. [9] & $199 / 215$ & $\mathrm{KPS} \geq 70$ & III-IV & $\mathrm{NP}, \mathrm{TP}+\mathrm{Rg} 3(40 \mathrm{mg} / \mathrm{d}, \mathrm{d} 1-\mathrm{d} 21)$ & NP, TP & (4) (5) (6) \\
\hline Yu et al. [10] & $57 / 45$ & KPS $>50$ & $\begin{array}{l}\text { IIIb- } \\
\text { IV }\end{array}$ & $\mathrm{GP}+\operatorname{Rg} 3(40 \mathrm{mg} / \mathrm{d}, \mathrm{d} 1-\mathrm{d} 56)$ & GP & $(1)(3)(4)(5)(6)(7)(8)$ \\
\hline Shi $[11]$ & $31 / 31$ & KPS $>60$ & Ib-IIIa & $\mathrm{PC}+\operatorname{Rg} 3(40 \mathrm{mg} / \mathrm{d}, \mathrm{d} 1-\mathrm{d} 28)$ & $\mathrm{PC}$ & (8) (9) \\
\hline Shen et al. [12] & $25 / 27$ & NR & $\begin{array}{l}\text { IIIb- } \\
\text { IV }\end{array}$ & $\mathrm{AP}, \mathrm{GP}+\mathrm{Rg} 3$ (40 mg/d, d1-d56) & AP, GP & (1) (2) \\
\hline Wang et al. [13] & $45 / 44$ & NR & $\begin{array}{l}\text { IIIb- } \\
\text { IV }\end{array}$ & TP, PC, GP, NP + Rg3 (40 mg/d, d1-d42) & TP, PC, GP, NP & (1) (3) (7) \\
\hline $\mathrm{Li}$ and Bai $[14]$ & $90 / 90$ & NR & NR & $\mathrm{GP}+\operatorname{Rg} 3(40 \mathrm{mg} / \mathrm{d}, \mathrm{d} 1-\mathrm{d} 49)$ & GP & $(1)(4)(6)(7)$ \\
\hline Liang and Han [15] & $47 / 46$ & $\mathrm{KPS} \geq 60$ & IIIa-IV & $\mathrm{GP}+\operatorname{Rg} 3(40 \mathrm{mg} / \mathrm{d}, \mathrm{d} 1-\mathrm{d} 60)$ & GP & (3) (9) \\
\hline Zhang et al.,[16] & $39 / 39$ & $\mathrm{KPS} \geq 70$ & IIIIV & $\mathrm{NP}+\mathrm{Rg} 3$ (40 mg/d, d1-d60) & NP & $(1)$ \\
\hline Wang [17] & $30 / 30$ & NR & Ib-IIIa & $\mathrm{AP}, \mathrm{PC}+\mathrm{Rg} 3(40-50 \mathrm{mg} / \mathrm{d}, \mathrm{d} 1-\mathrm{d} 60)$ & AP, PC & (8) \\
\hline Liu et al. [18] & $60 / 60$ & NR & III-IV & $\mathrm{NP}+\operatorname{Rg} 3(40 \mathrm{mg} / \mathrm{d}, \mathrm{d} 1-\mathrm{d} 20)$ & NP & $(1)$ \\
\hline Liu et al. [19] & $22 / 19$ & $\mathrm{KPS} \geq 60$ & III-IV & $\mathrm{NP}, \mathrm{TP}+\mathrm{Rg} 3$ (40 mg/d, d1-d60) & NP, TP & $(1)(2)(4)(5)(6)(7)$ \\
\hline Li et al. [20] & $22 / 22$ & NR & NR & $\mathrm{EP}+\operatorname{Rg} 3(40 \mathrm{mg} / \mathrm{d}, \mathrm{d} 1-\mathrm{d} 28)$ & EP & (1) (4) (6) (7) \\
\hline Du [21] & $30 / 30$ & KPS $>70$ & III-IV & $\mathrm{TP}+\operatorname{Rg} 3$ (40 mg/d, d1-d21) & $\mathrm{TP}$ & (1) $(3)$ \\
\hline $\mathrm{Li}$ and $\mathrm{Li}[22]$ & $106 / 108$ & NR & III-IV & $\mathrm{GP}+\mathrm{Rg} 3(40 \mathrm{mg} / \mathrm{d}, \mathrm{d} 1-\mathrm{d} 60)$ & GP & (1) $(8)$ \\
\hline Li et al. [23] & $39 / 38$ & $\mathrm{KPS} \geq 60$ & III-IV & $\mathrm{GP}+\operatorname{Rg} 3(40 \mathrm{mg} / \mathrm{d}, \mathrm{d} 1-\mathrm{d} 60)$ & GP & (1) (2) (3) (4) (5) (7) \\
\hline Chen and $\mathrm{Li}$ [24] & $35 / 35$ & KPS $>50$ & III-IV & $\mathrm{GP}+\operatorname{Rg} 3(40 \mathrm{mg} / \mathrm{d}, \mathrm{d} 1-\mathrm{d} 21)$ & GP & (1) (3) (4) (5) (6) (7) \\
\hline Wang et al. [31] & $59 / 58$ & KPS $>60$ & $\begin{array}{l}\text { IIIb- } \\
\text { IV }\end{array}$ & GP, NP + Rg3 (40 mg/d, d1-d56) & GP, NP & (3) (7) (9) \\
\hline Qin et al. [26] & $20 / 20$ & $\mathrm{KPS} \geq 70$ & II-IIIa & $\mathrm{GP}+\operatorname{Rg} 3(40 \mathrm{mg} / \mathrm{d}, \mathrm{d} 1-\mathrm{d} 28)$ & GP & (3) (4) (8) (9) \\
\hline Qi and Zhang [21] & $35 / 35$ & $\mathrm{KPS}>60$ & III-IV & $\mathrm{GP}+\operatorname{Rg} 3(40 \mathrm{mg} / \mathrm{d}, \mathrm{d} 1-\mathrm{d} 21)$ & GP & (1) (3) \\
\hline Zhang et al. [28] & $46 / 44$ & KPS $>70$ & II-IIIa & $\mathrm{GP}+\operatorname{Rg} 3(40 \mathrm{mg} / \mathrm{d}, \mathrm{d} 1-\mathrm{d} 56)$ & GP & (2) \\
\hline Liu et al. [29] & $34 / 30$ & $\mathrm{KPS} \geq 60$ & $\begin{array}{c}\text { IIIb- } \\
\text { IV }\end{array}$ & $\mathrm{NP}+\mathrm{Rg} 3(40 \mathrm{mg} / \mathrm{d}, \mathrm{d} 1-\mathrm{d} 56)$ & NP & $(1)(2)(4)(5)(6)(7)$ \\
\hline Lu et al. [30] & $46 / 44$ & KPS $>70$ & II-IIIa & $\mathrm{NP}, \mathrm{GP}+\mathrm{Rg} 3(40-50 \mathrm{mg} / \mathrm{d}, \mathrm{d} 1-\mathrm{d} 180)$ & NP, GP & $(2)(4)(7)$ \\
\hline Liu and Liu. [31] & $35 / 33$ & $\mathrm{KPS} \geq 60$ & $\begin{array}{l}\text { IIIb- } \\
\text { IV }\end{array}$ & $\mathrm{NP}+\operatorname{Rg} 3(40 \mathrm{mg} / \mathrm{d}, \mathrm{d} 1-\mathrm{d} 42)$ & NP & (1) (3) (4) (5) (6) (7) (8) \\
\hline Liu et al. [32] & $35 / 35$ & KPS $>60$ & $\begin{array}{l}\text { IIIb- } \\
\text { IV }\end{array}$ & $\mathrm{NP}+\operatorname{Rg} 3(40 \mathrm{mg} / \mathrm{d}, \mathrm{d} 1-\mathrm{d} 39)$ & NP & (1) (3) (8) \\
\hline Sun et al. [33] & $51 / 55$ & KPS $>60$ & III-IV & $\mathrm{NP}+\mathrm{Rg} 3$ (40 mg/d, d1-d21) & NP & $(1)(4)(5)(6)$ \\
\hline Shi et al. [34] & $22 / 19$ & $\mathrm{KPS} \geq 60$ & III-IV & $\mathrm{NP}+\operatorname{Rg} 3$ (40 mg/d, d1-d180) & NP & $(1)(2)(4)(5)(6)(7)$ \\
\hline Lin et al. [35] & $120 / 31$ & KPS $>60$ & II-IV & $\mathrm{EP}+\operatorname{Rg} 3$ (40 mg/d, d1-d42) & $\mathrm{EP}$ & (1) (3) (8) \\
\hline
\end{tabular}

Note. (1) T: treatment group, C: control group; Rg3 : Shenyi capsule; GP: gemcitabine + cis-platinum; TP: taxol + cis-platinum; NP: navelbine + cis-platinum; AP: pemetrexed + cis-platinum; PC: pemetrexed + carboplatin; TC: taxol + carboplatin; EP: etoposide + cis-platinum. (2) Shenyi capsule was oral administration; (3) outcome index; (1) tumour objective remission rate; (2) survival rate; (3) KPS; (4) leukocyte toxicity; (5) haemoglobin toxicity; (6) platelet toxicity; (7) vomiting; (8) immune function; (9) serum VEGF.

These patients are already in advanced stages of NSCLC and have missed the optimal chance for operation. At present, the combination of third-generation chemotherapy with platinum-based drug is the standard first-line strategy for NSCLC, for which a majority of patients require venous injection and hospitalisation. Although platinum-based chemotherapy can inhibit the spread of cancer cells, adverse events including toxicity and side-effects in the gastrointestinal tract and marrow are widespread [38]. These effects severely reduce immune function and degrade patient quality of life; moreover, the 1-year survival rate $<40 \%$. Although targeted drugs can be taken orally, they are expensive and are not affordable for patients consistent with the maintenance stage.

Chinese medicines are treasures of the China civilisation and the essence of a 5,000-year culture. The ancillary efficacy of Chinese medicines for tumour treatment is definite, in addition to the limited side-effects. Although Chinese medicines are limited in their ability to shrink tumours, they help to improve patient symptoms, stabilise tumours, and improve patient quality of life, leading to long-term, highquality survival with tumours $[39,40]$.

Ginseng, a traditional Chinese medicine, can invigorate vital energy, restore routine pulse, rehabilitate collapse, nourish the spleen, benefit the lungs, increase intelligence, and soothe the mind. Shenyi capsule is a class I monomer anti-tumour drug in China. Its main bioactive ingredient is the monomer ginsenoside, Rg3, which is extracted from ginseng. $\operatorname{Rg} 3$ is a tetracyclic triterpenoid saponin. Studies have confirmed that Rg3 inhibits tumour growth. Rg3 induces apoptosis of tumour cells in their G2/M proliferative cycle and inhibits tumour neovascularisation, leading to selective inhibition of tumour cell infiltration and adhesion and inhibition of tumour metastasis. In addition, $\mathrm{Rg} 3 \mathrm{can}$ also regulate the immune function of the human body [41].

Several clinical studies $[10,13,14,19,20,23-25,29-31,34]$ have shown that Shenyi capsules synergise the effect and reduce the toxicity of platinum-based chemotherapy for 

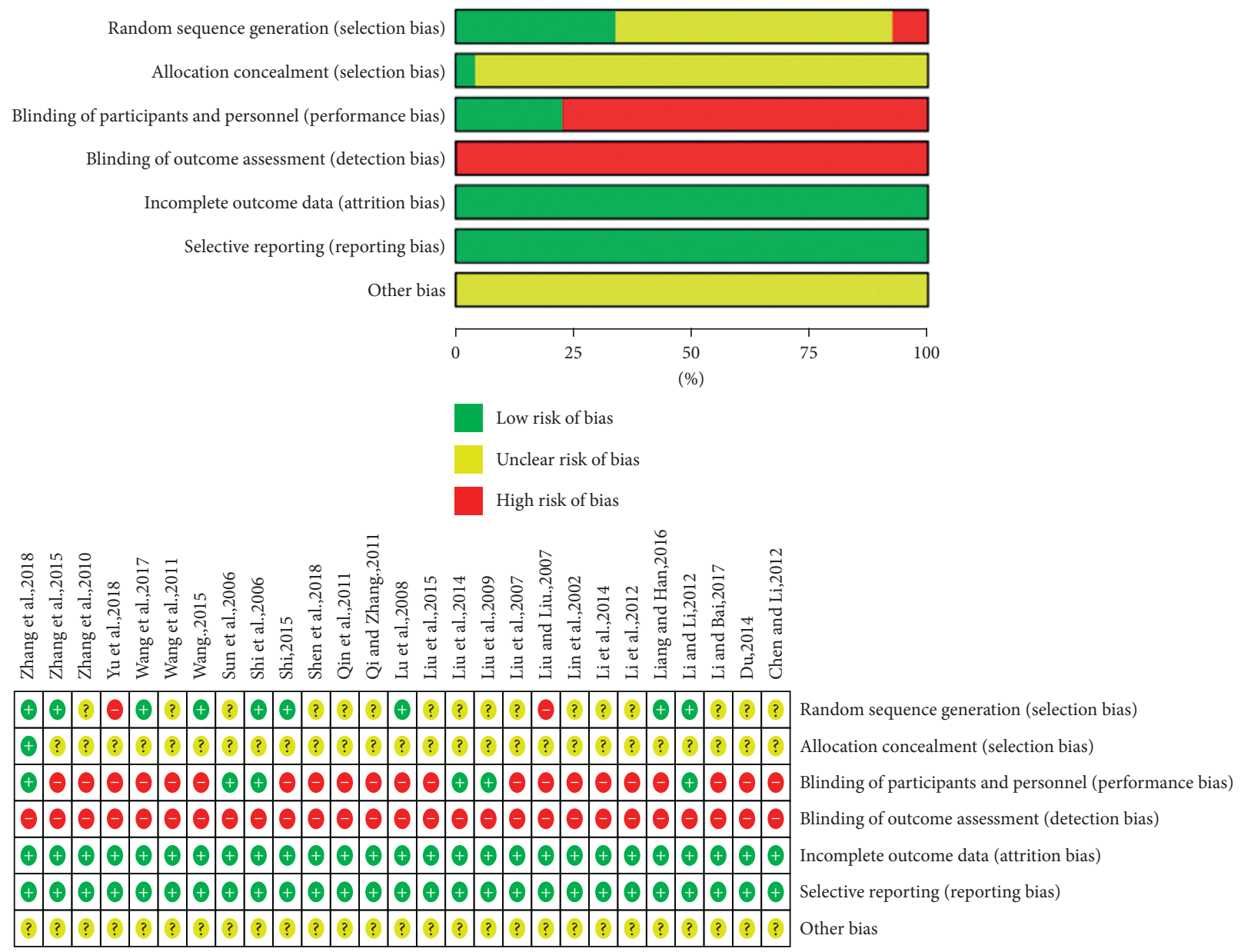

FIgURE 3: Risk of bias in included studies.

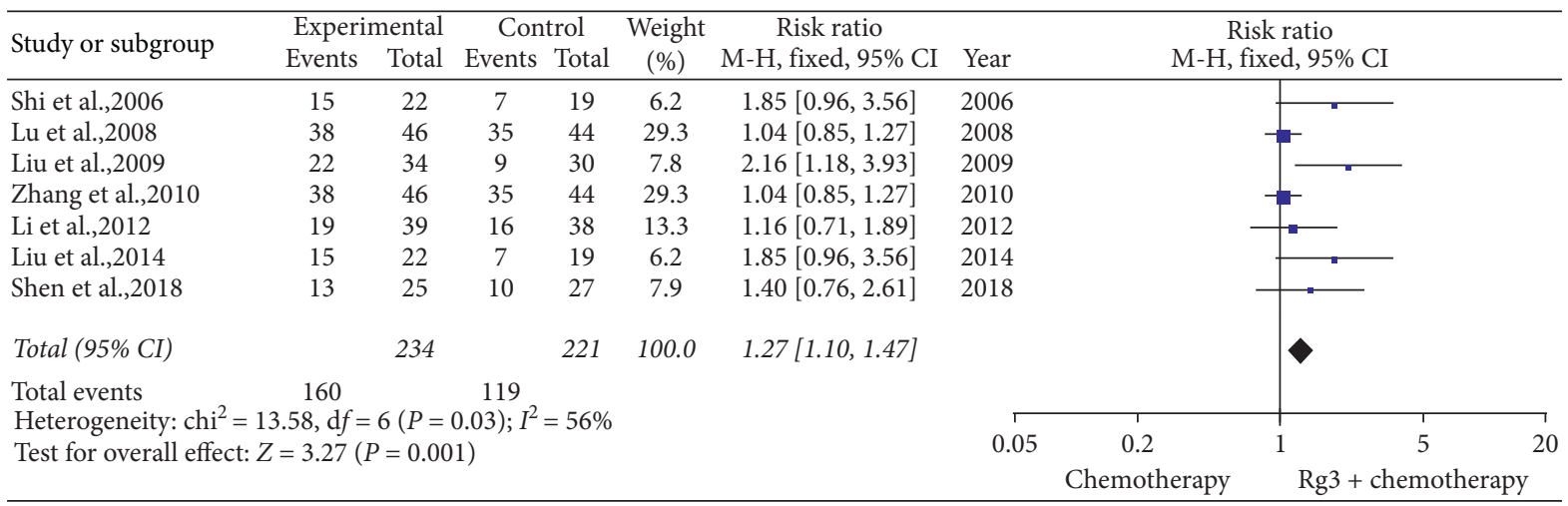

FIgURE 4: Meta-analysis of 1-year survival rate in included studies.

NSCLC. Although this treatment strategy has few side-effects and is generally well-tolerated, evidence-based data are lacking. The present meta-analysis included 27 reports of RCTs. The results showed increased clinical efficacy and quality of life in the treatment group (combined treatment using both Shenyi capsules and platinum-based chemotherapy) compared to those in the control group (treatment using only platinum-based chemotherapy). In terms of safety, the use of Shenyi capsules reduced the toxicity and side-effects of chemotherapy.

One- and two-year survival rates are both used as important indicators in RCTs. They directly reflect patient benefits of survival and are considered gold standards to assess curative efficacy. Among the studies included in the current metaanalysis, seven and six reported 1- and 2-year survival rates, respectively. Both showed positive results, suggesting that 


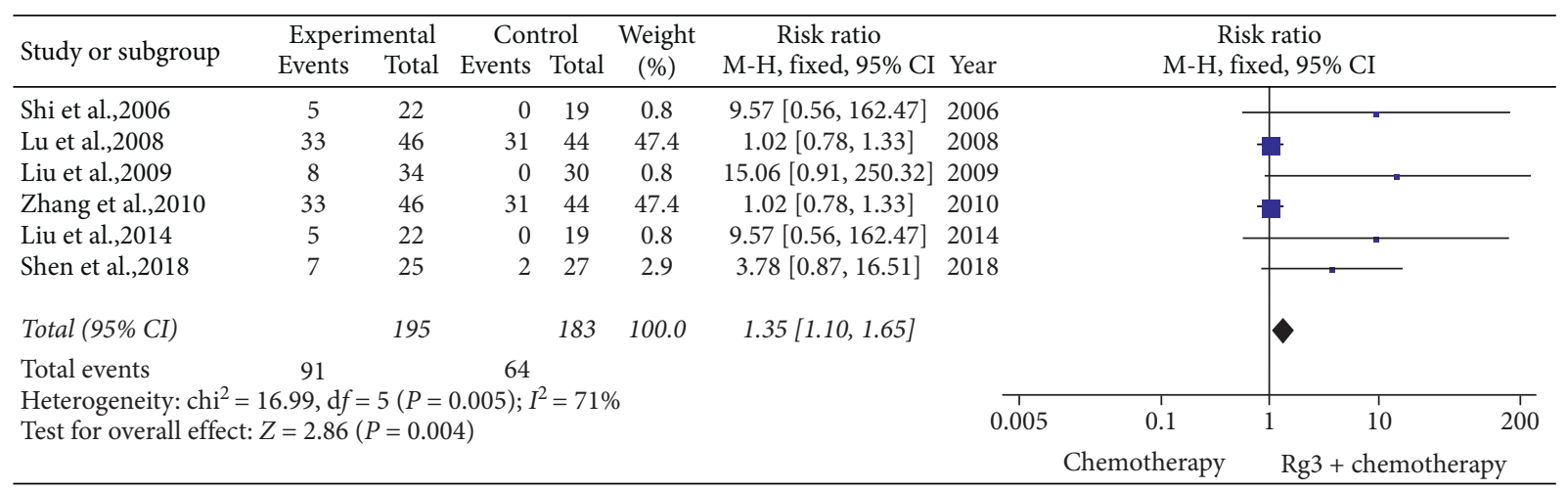

FIgURE 5: Meta-analysis of 2-year survival rate in included studies.

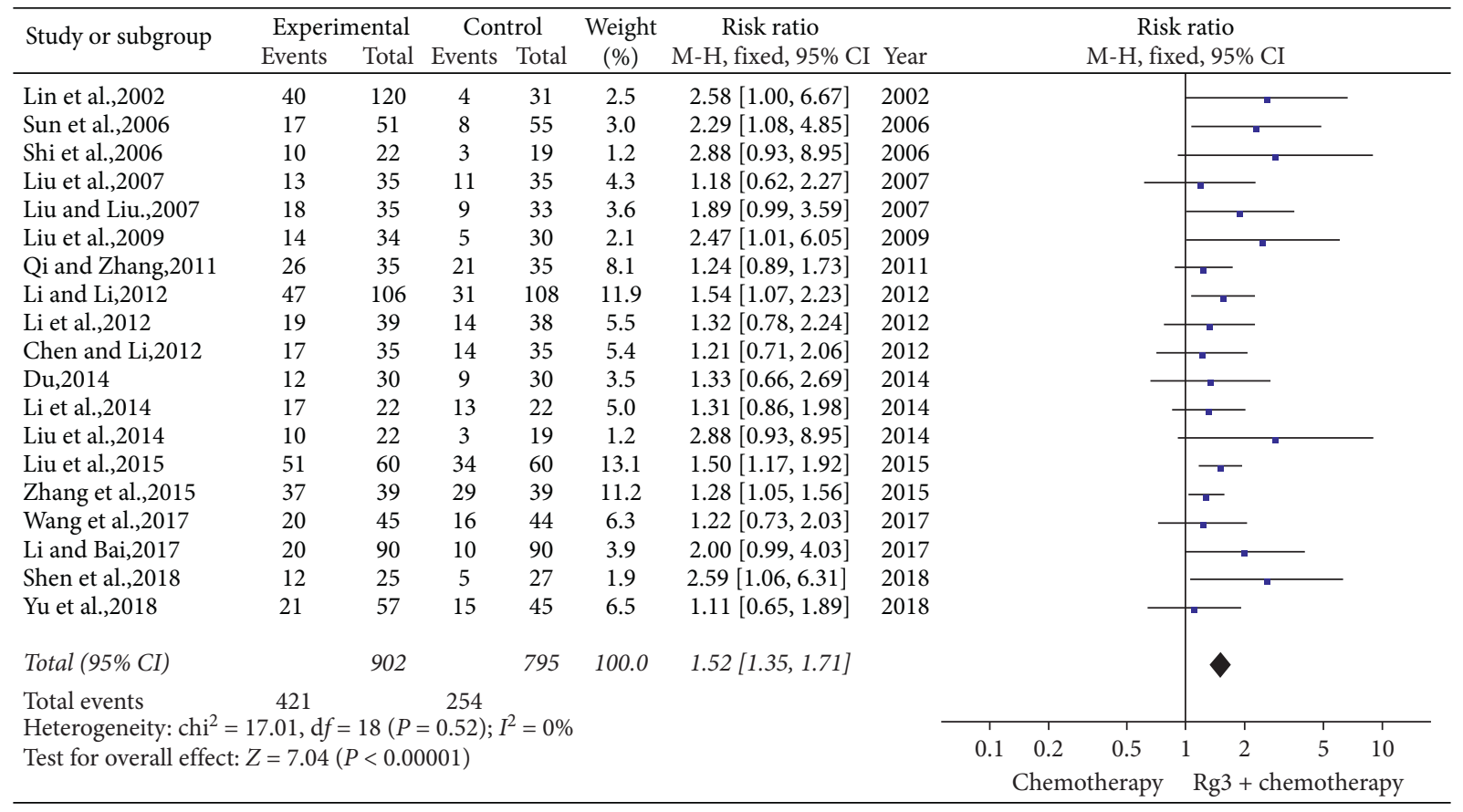

FIGURE 6: Meta-analysis of short-term efficacy in included studies.

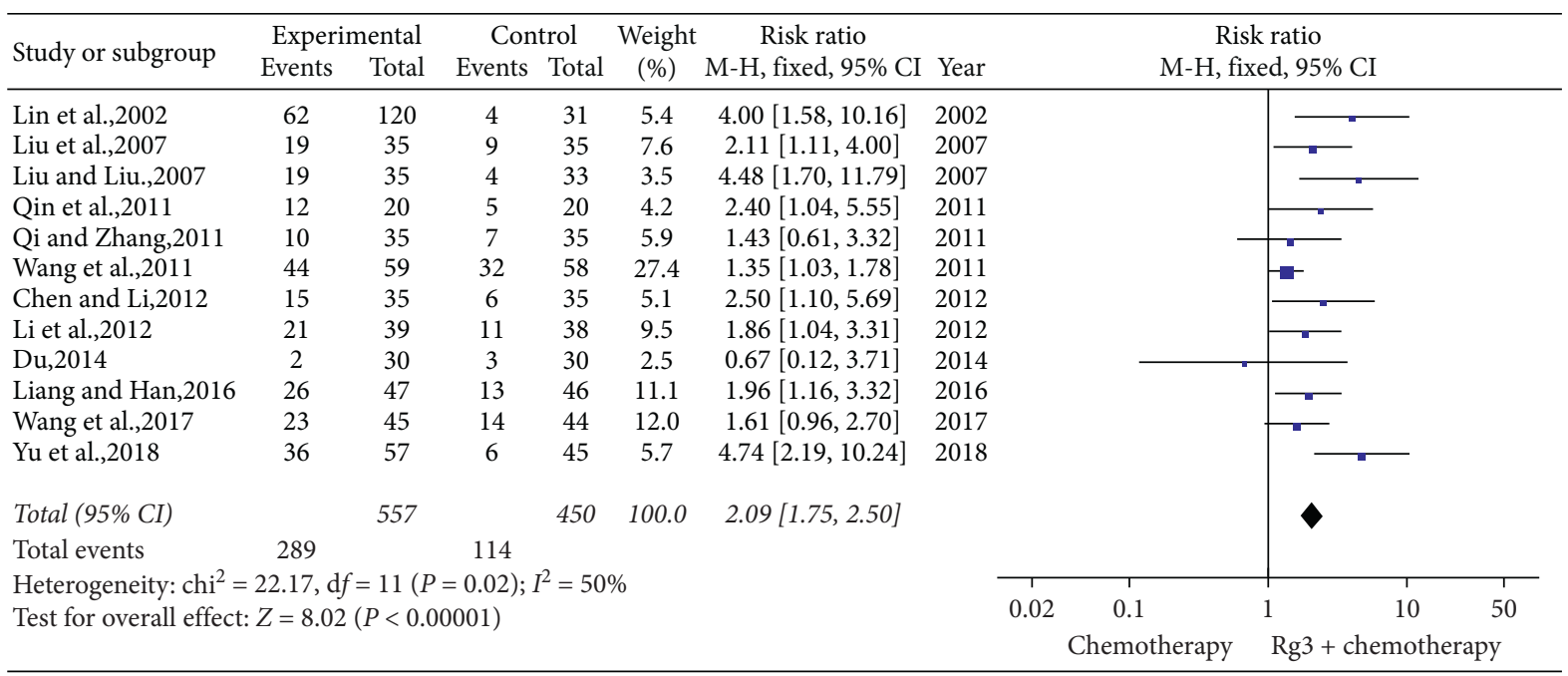

Figure 7: Meta-analysis of life qualities in included studies. 


\begin{tabular}{|c|c|c|c|c|c|c|c|c|c|c|}
\hline \multirow{3}{*}{$\begin{array}{l}\text { Study or subgroup } \\
\text { Chen and Li,2012 }\end{array}$} & \multicolumn{2}{|c|}{ Experimental } & \multicolumn{2}{|c|}{ Control } & \multirow{2}{*}{$\begin{array}{c}\text { Weight } \\
(\%)\end{array}$} & \multirow{2}{*}{\multicolumn{2}{|c|}{$\begin{array}{c}\text { Risk ratio } \\
\text { M-H, fixed, 95\% CI }\end{array}$}} & \multirow{2}{*}{\multicolumn{2}{|c|}{$\begin{array}{c}\text { Risk ratio } \\
\text { M-H, fixed, 95\% CI }\end{array}$}} & \\
\hline & Events & Total & Events & Total & & & & & & \\
\hline & 2 & 35 & 7 & 35 & 4.6 & $0.29[0.06,1.28]$ & & & & \\
\hline Li and Bai,2017 & 4 & 90 & 0 & 90 & 0.3 & $9.00[0.49,164.76]$ & & - & & \\
\hline Li et al.,2012 & 5 & 39 & 16 & 38 & 10.7 & $0.30[0.12,0.75]$ & & $\longrightarrow$ & & \\
\hline Li et al.,2014 & 6 & 22 & 12 & 22 & 7.9 & $0.50[0.23,1.09]$ & & 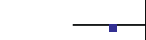 & & \\
\hline Liu and Liu.,2007 & 5 & 35 & 12 & 33 & 8.2 & $0.39[0.16,0.99]$ & & 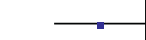 & & \\
\hline Lin et al.,2009 & 6 & 34 & 5 & 30 & 3.5 & $1.06[0.36,3.12]$ & & & & \\
\hline Liu et al.,2014 & 12 & 22 & 16 & 19 & 11.4 & $0.65[0.42,0.99]$ & & $\longrightarrow$ & & \\
\hline Lu et al.,2008 & 4 & 46 & 3 & 44 & 2.0 & $1.28[0.30,5.38]$ & & & & \\
\hline Qin et al.,2011 & 0 & 20 & 1 & 20 & 1.0 & $0.33[0.01,7.72]$ & & & & \\
\hline Shi et al.,2006 & 6 & 22 & 6 & 19 & 4.3 & $0.86[0.33,2.23]$ & & 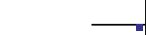 & & \\
\hline Sun et al.,2006 & 10 & 51 & 17 & 55 & 10.8 & $0.63[0.32,1.25]$ & & $\longrightarrow$ & & \\
\hline Yu et al.,2018 & 3 & 57 & 21 & 45 & 15.5 & $0.11[0.04,0.35]$ & & - & & \\
\hline Zhang et al.,2018 & 12 & 199 & 31 & 215 & 19.7 & $0.42[0.22,0.79]$ & & - & & \\
\hline Total (95\% CI) & & 672 & & 665 & 100.0 & $0.49[0.39,0.63]$ & & $\diamond$ & & \\
\hline Total events & 75 & & 147 & & & & & & & \\
\hline \multirow{2}{*}{\multicolumn{7}{|c|}{$\begin{array}{l}\text { Heterogeneity: } \mathrm{chi}^{2}=19.39, \mathrm{~d} f=12(P=0.08) ; I^{2}=38 \% \\
\text { Test for overall effect: } Z=5.74(P<0.00001)\end{array}$}} & 0.005 & 0.1 & 10 & 200 \\
\hline & & & & & & & $\mathrm{Rg}$ & emotherapy & Chemot & \\
\hline
\end{tabular}

Figure 8: Meta-analysis of extent of leukocyte in included studies.

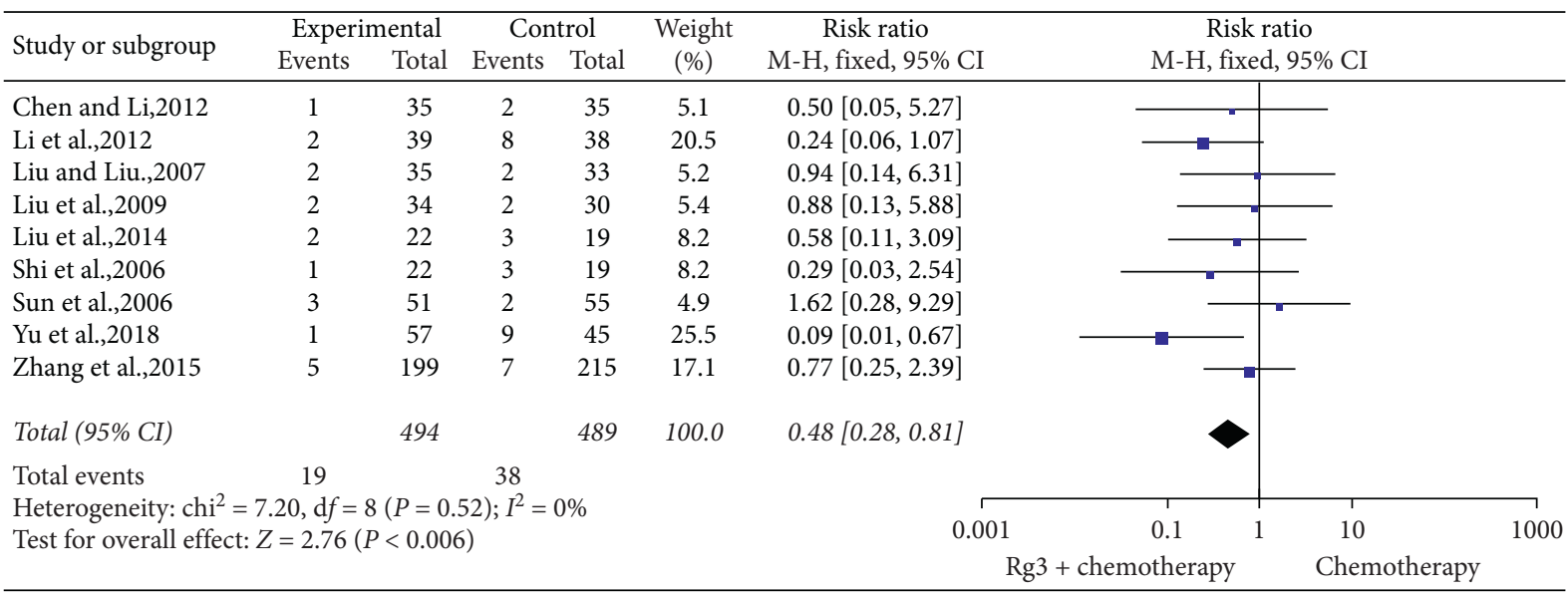

Figure 9: Meta-analysis of extent of haemoglobin in included studies.

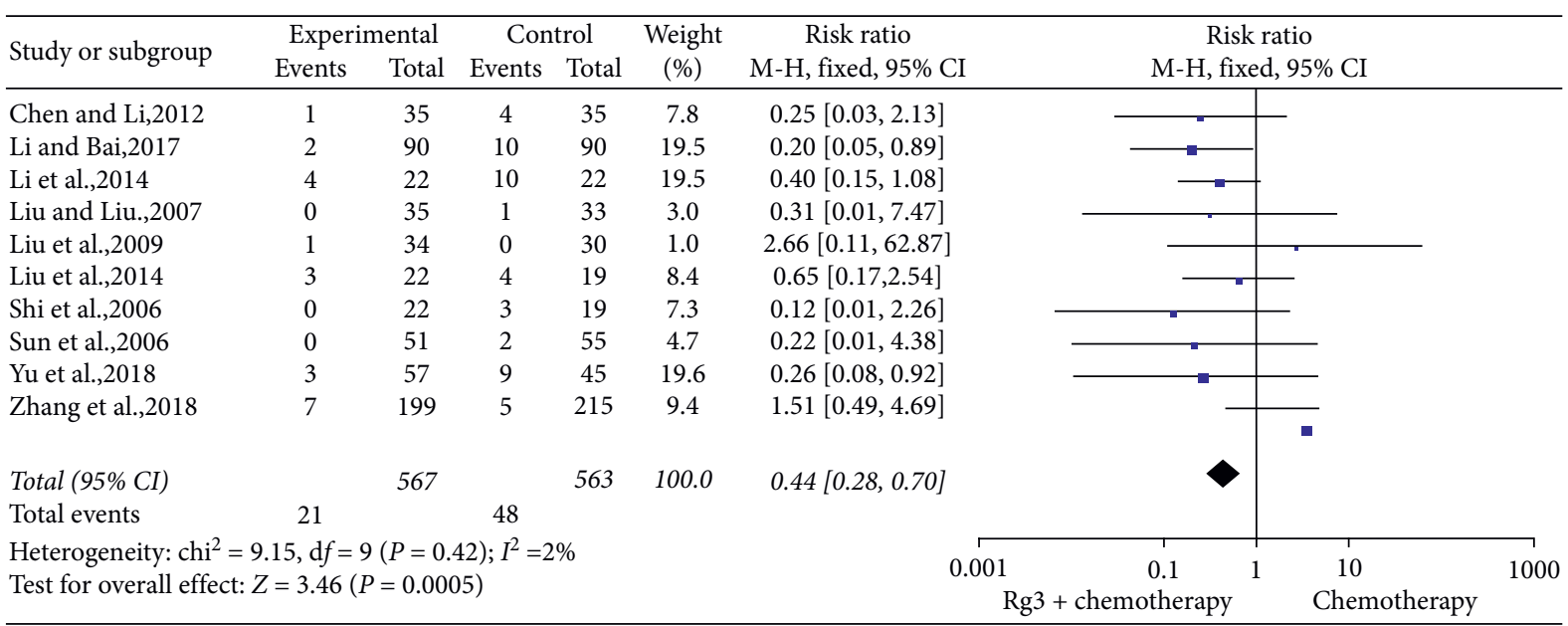

Figure 10: Meta-analysis of extent of platelet in included studies. 


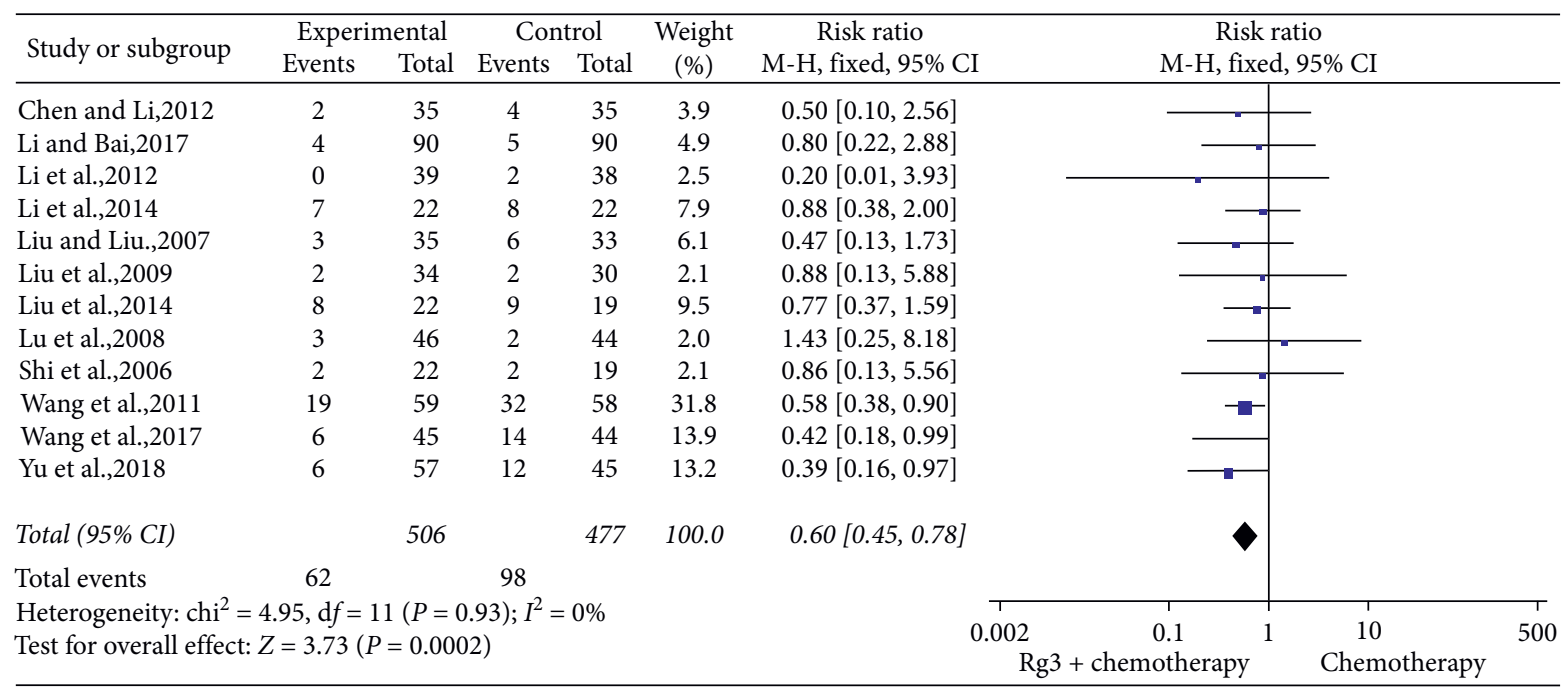

FIGURE 11: Meta-analysis of vomiting response in included studies.

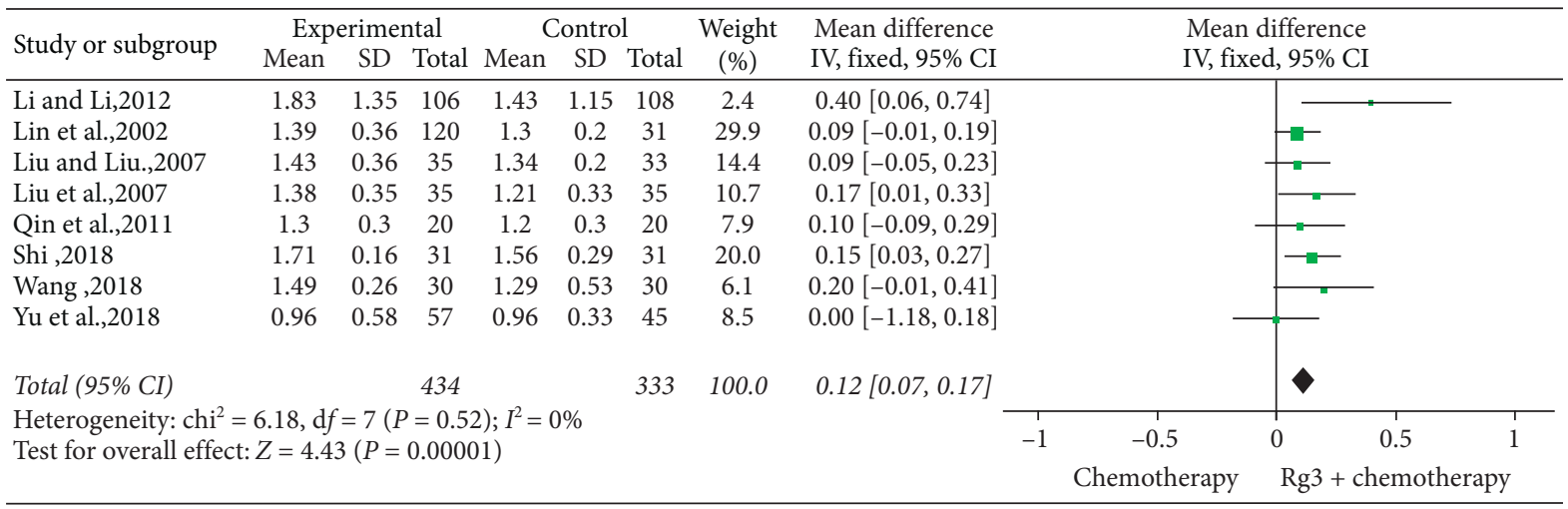

Figure 12: Meta-analysis of $\mathrm{CD} 4^{+} / \mathrm{CD} 8{ }^{+}$levels in included studies.

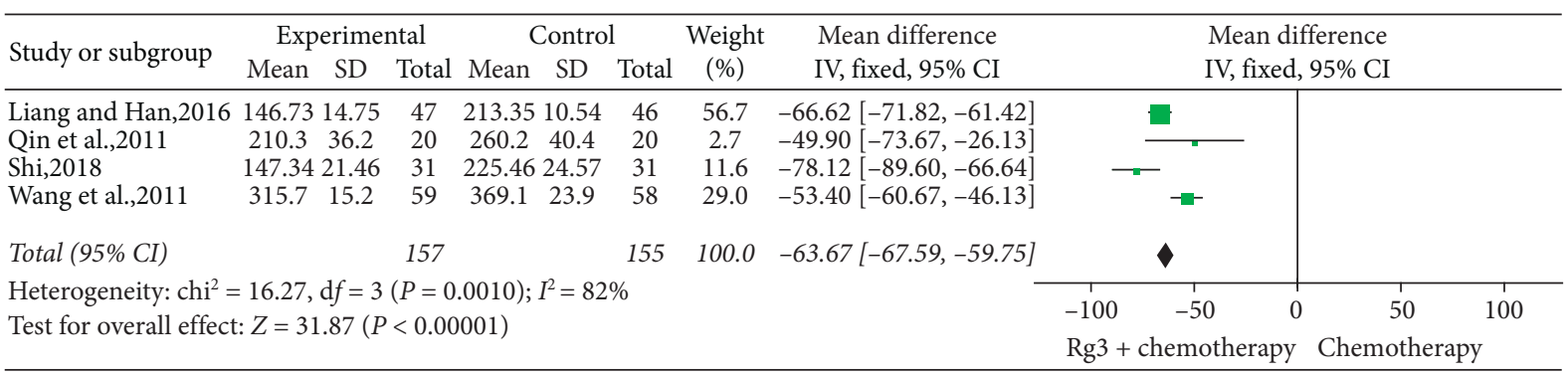

Figure 13: Meta-analysis of VEGF levels in included studies.

combined treatment with Shenyi capsules and platinum-based chemotherapy could increase patient survival time. This finding has significance for clinical medication.

Peripheric subgroups of lymphocytes are important indicators that can reflect general immune function, immune status, and immune equilibrium and can be used to observe efficacy and test prognosis. $\mathrm{CD}^{+}$and $\mathrm{CD} 8^{+}$are $\mathrm{T}$ lymphocytes. A reduction in the $\mathrm{CD} 4^{+} / \mathrm{CD} 8^{+}$ratio is common in lung cancer patients after chemotherapy cycles, indicating an inhibition of the immune function in which the immune system's ability to recognise and kill mutant cells is weakening, leading to tumour growth and metastasis. Rg3, a ginseng extract and Chinese medicine, improves patient immunity. The results of the present study confirmed that Shenyi capsules could inhibit the reduction of $\mathrm{CD}^{+}$/ $\mathrm{CD}^{+}$ratio in NSCLC patients subjected to chemotherapy. 


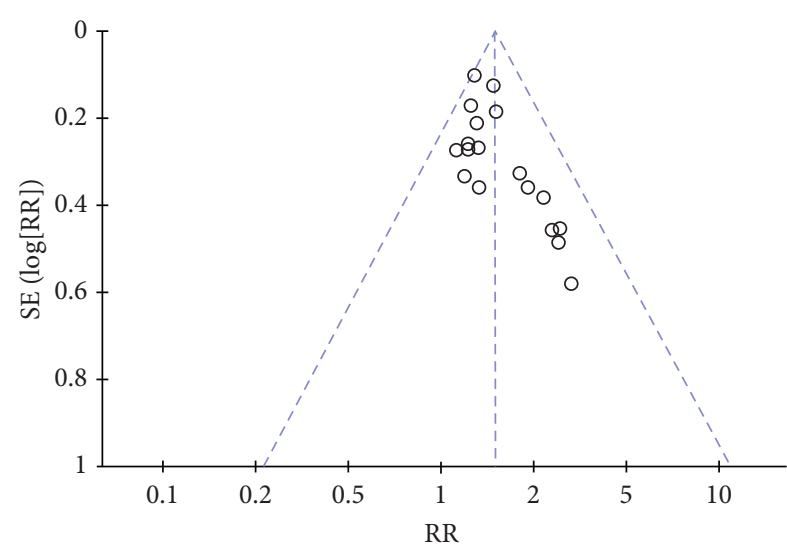

(a)

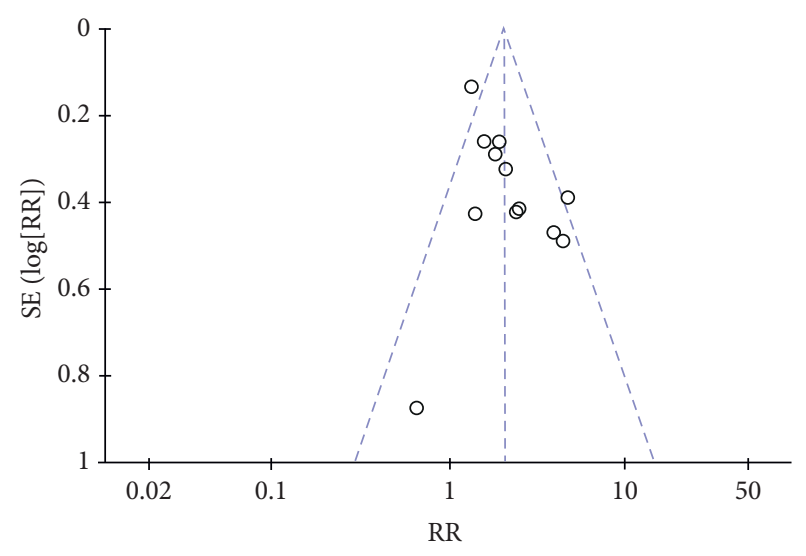

(b)

FIGURE 14: Funnel plots for publication biases in included studies: (a) objective tumour response and (b) KPS.

Angiogenesis is a marker of rapid tumour growth and metastasis, as well as an important indicator of cancer progression. VEGF can induce neovascularisation in vivo and maintain persistent tumour growth. It is the most powerful angiogenic factor found to date and an important medium for NSCLC angiogenesis. Therefore, treatment targeting antiangiogenesis agents or anti-VEGF pathways are effective approaches for the treatment of lung cancer. Research has shown that $\mathrm{Rg} 3$ can inhibit the cohesion, infiltration, and blood vessel penetration of tumour cells by inhibiting the generation of VEFG and further halt tumour growth and metastasis. The results of the present study confirmed that Shenyi capsules can reduce peripheral VEGF levels in patients with NSCLC.

The 27 reports of RCTs were selected according to the inclusion criteria, exclusion criteria, and quality scores. Publication bias was evaluated based on funnel plots. The indicators were evaluated using the Cochrane risk assessment table. However, the study has the following limitations:

(1) The studies included in the meta-analysis were conducted in China; thus, there is some racial bias that may affect the results.

(2) Most of the studies included in the meta-analysis did not describe the methods of blinding or allocation concealment, which likely led to implementation and measurement biases.

(3) This study lacks reports from multicentred and largesized RCTs. As most of the studies included in the present meta-analysis were single-centre studies with small sample numbers, there was some clinical heterogeneity that may have affected the results and the strength of the evidence.

(4) No domestic or international standard of treatment is yet available for the treatment of NSCLC. Therefore, the platinum-based chemotherapeutic strategies differed between studies. Even if the same chemotherapeutic strategy was adopted, the dosage and course of treatment differed, which inevitably increases the heterogeneity of clinical studies.
(5) There was publication bias among the studies included in the meta-analysis. As positive results are easier to publish than negative ones, it is challenging to find the unpublished grey literature. Moreover, less rigorous experimental design, incomplete or inconsistent preventative measures, and small sample sizes can all cause light degrees of heterogeneity. To reduce methodological heterogeneity and reporting bias and to further improve the research quality of evidence-based medicine, clinical studies should refer to high-quality experiment designs abroad, double-blinded and allocation concealment methods should be adopted, and loss-to-follow-up and drop-outs should be analysed.

\section{Conclusions}

In summary, our meta-analysis of 27 RCTs concluded that the combined treatment of NSCLC using both Shenyi capsule and platinum-based chemotherapeutical strategy is safe and effective and could enhance the short- and longterm effects of chemotherapy, improve patient quality of life, reduce the toxicity and side-effects of platinum-based chemotherapeutic drugs, increase immune function, and inhibit tumour neovascularisation. The results of this analysis were limited by the quantity and quality of the studies included in the meta-analysis; therefore, the results of the present study require validation in large-sized, multicentred, and high-quality RCTs.

\section{Data Availability}

The data used to support the finding of this study are available from the corresponding author upon request.

\section{Disclosure}

Yong $\mathrm{Xu}$ and Wenpan Peng should be regarded as the cofirst authors. 


\section{Conflicts of Interest}

The authors declare they have no conflicts of interest.

\section{Authors' Contributions}

X. Z. and Q. W. contributed conception and design of the study. Y. X. searched the database, evaluated studies for inclusion, extracted data, and then crosschecked with W. P. In addition, D. H., Z. W., C. G., and F. F. assisted in literature retrieval and data analysis. Y. X. wrote the first draft of the manuscript; W. P., D. H., Z. W., C. G., and F. F. wrote sections of the manuscript. X. Z. and Q. W. were responsible for quality control of the study. All the authors approved on the final version of this article. Yong Xu and Wenpan Peng contributed to the work equally.

\section{Acknowledgments}

This work was finically funded by the National Natural Science Foundation of China (81673936) and Jiangsu Province's Colleges and Universities (integration of Chinese and Western medicine).

\section{References}

[1] F. Bray, J. Ferlay, I. Soerjomataram et al., "Global cancer statistics 2018: GLOBOCAN estimates of incidence and mortality worldwide for 36 cancers in 185 countries," CA: A Cancer Journal for Clinicians, vol. 68, no. 6, pp. 394-424, 2018.

[2] W.-L. Tan, A. Jain, A. Takano et al., "Novel therapeutic targets on the horizon for lung cancer," The Lancet Oncology, vol. 17, no. 8, pp. e347-e362, 2016.

[3] F. C. Detterbeck, K. Chansky, P. Groome et al., "The IASLC lung cancer staging project: methodology and validation used in the development of proposals for revision of the stage classification of NSCLC in the forthcoming (eighth) edition of the TNM classification of lung cancer," Journal of Thoracic Oncology: Official Publication of the International Association for the Study of Lung Cancer, vol. 11, no. 9, pp. 1433-1446, 2016.

[4] G. D’Addario, M. Pintilie, N. B. Leighl et al., "Platinum-based versus non-platinum-based chemotherapy in advanced nonsmall-cell lung cancer: a meta-analysis of the published literature," Journal of Clinical Oncology, vol. 23, no. 13, pp. 2926-2936, 2005.

[5] D. D. Ruysscher, C. Faivre-Finn, K. Nackaerts et al., "Recommendation for supportive care in patients receiving concurrent chemotherapy and radiotherapy for lung cancer," Annals of Oncology, vol. 31, no. 1, pp. 41-49, 2020.

[6] J. Wang, L. Tian, M. N. Khan et al., "Ginsenoside Rg3 sensitizes hypoxic lung cancer cells to cisplatin via blocking of NF- $\kappa \mathrm{B}$ mediated epithelial-mesenchymal transition and stemness," Cancer Letters, vol. 415, pp. 73-85, 2018.

[7] X.-W. Guo, N.-D. Hu, G.-Z. Sun, M. Li, and P.-T. Zhang, "Shenyi capsule () plus chemotherapy versus chemotherapy for non-small cell lung cancer: a systematic review of overlapping meta-analyses," Chinese Journal of Integrative Medicine, vol. 24, no. 3, pp. 227-231, 2018.

[8] M. K. Wilson, K. Karakasis, A. M. Oza et al., "Outcomes and endpoints in trials of cancer treatment: the past, present, and future," The Lancet Oncology, vol. 16, no. 1, pp. e32-e42, 2015.
[9] Y. Zhang, X. Wang, H. Liu et al., "A multicenter, large-sample, randomized clinical trial on improving the median survival time of advanced non-small cell lung cancer by combination of Ginseng Rg3 and chemotherapy," Chinese Journal of Oncology, vol. 40, no. 4, pp. 295-299, 2018.

[10] T.-Y. Yu, H.-Z. Cui, S.-N. Zhang, and L.-X. Ma, "Impact analysis of clinical effect of chemotherapy and immunologic function on advanced NSCLC with shenyi capsule," Chinese Journal of Immunology, vol. 34, no. 7, pp. 1012-1016, 2018.

[11] Z. Shi, "Effects of ginsenoside Rg3 capsules on serum TGF- $\beta 1$, VEGF and immune function in patients with non-small cell lung cancer," Heilongjiang Medicine and Pharmacy, vol. 41, no. 6, pp. 186-187+189, 2018.

[12] K. Shen, W. Zhou, and Z. Ye, "Effect observation of Shenyi capsule combined with chemotherapy on treating senile patients with advanced non-small cell lung cancer," Journal of Clinical Medicine in Practice, vol. 23, pp. 123-124, 2018.

[13] G. Wang, F. Liu, Z. Zhang et al., "The study of serum matrix metalloproteinase- 9 and its inhibitor and the efficacy of Shenyi capsule combined with chemotherapy in the treatment of advanced NSCLC," Journal of Modern Oncology, vol. 25, no. 6, pp. 896-901, 2017.

[14] Y. Li and W. Bai, "Shenyi capsule combined with GP regimen in the treatment of non-small cell lung cancer clinical analysis," Liaoning Journal of Traditional Chinese Medicine, vol. 44, no. 3, pp. 553-555, 2017.

[15] J. Liang and X. Han, "Effect of ginsenoside Rg3 combined with chemotherapy on serum VEGF,TGF- $\beta 1$ and TGF- $\alpha$ in patients with advanced non-small cell lung cancer," Journal of Clinical Pulmonary Medicine, vol. 21, no. 9, pp. 1675-1678, 2016.

[16] H. Zhang, Y. Li, and L. Su, "Observation of the efficacy of NP regimen combined with Shenyi capsule in the treatment of elderly patients with advanced non-small cell lung cancer," Medical Information, vol. 15, pp. 252-253, 2015.

[17] Z. Wang, "Effect of shenyi capsule on phenotype of peripheral lymphocytes in non-small cell lung cancer and its mechanism," Yunnan Journal of Traditional Chinese Medicine and Materia Medica, vol. 36, no. 7, pp. 34-35, 2015.

[18] S. Liu, R. Zhen, J. Cui, and K. Yin, "Clinical study of Shenyi capsule combined with first-line chemotherapy in the treatment of advanced non-small cell lung cancer," Journal of Clinical Medical Literature, vol. 24, pp. 5040-5041, 2015.

[19] S. Liu, H. Zhang, and J. Yao, "Clinical observation of Shenyi capsule adjuvant chemotherapy for advanced non-small cell lung cancer," Medical Frontier, vol. 21, pp. 22-23, 2014.

[20] M. Li, N. Jing, Z. Chen, and M. Yang, "Clinical evaluation of Shenyi capsule combined with EP regimen in the treatment of extensive small cell lung cancer," Modern Diagnosis and Treatment, vol. 10, pp. 2184-2185, 2014.

[21] L. Du, "Clinical observation of Shenyi Capsule in adjuvant treatment of advanced non-small cell lung cancer," Nei Mongol Journal of Traditional Chinese Medicine, vol. 33, no. 34, p. 7, 2014.

[22] K. Li and W. Li, "Clinical observation of Shenyi capsule combined with gemcitabine and cisplatin in the treatment of advanced lung cancer," World Health Digest, vol. 50, pp. 208-209, 2012.

[23] C. $\mathrm{Li}, \mathrm{Q}$. Li, and J. Xu, "Clinical study of GP regimen plus gensing Rg3 in treatment of advanced non-small cell lung cancer," Cancer Research on Prevention and Treatment, vol. 39, no. 9, pp. 1125-1127, 2012.

[24] S. Chen and R. Li, "Clinical observation of Shenyi capsule combined with GP regimen in the treatment of advanced non- 
small cell lung cancer," Contemporary Medicine, vol. 31, p. 1, 2012.

[25] Y. Wang, J. Liu, H. Zhao et al., "Clinical efficacy of ginsenoside Rg3 combined with chemotherapy treatment on non-smallcell lung cancer," Journal of Practical Oncology, vol. 25, no. 1, pp. 33-35, 2011.

[26] C. Qin, X. Kou, and Z. Miao, "Observation of ginsenoside Rg3 combined with chemotherapy as adjuvant treatment for elder nonsmall-cell lung cancer patients," Journal of Xinxiang Medical College, vol. 28, no. 2, pp. 229-230, 2011.

[27] C. Qi and H. Zhang, "Ginsenoside R93 combined GP regimen in the treatment of advanced non-small cell lung cancer," Journal of Clinical Medicine in Practice, vol. 11, no. 15, pp. 121-122, 2011.

[28] H. Zhang, X. Tian, S. Li et al., "Effect and mechanism of ginsenoside $\mathrm{Rg} 3$ on long-term survival after non-small cell lung cancer," National Medical Frontiers of China, vol. 5, no. 21, pp. 10-11, 2010.

[29] X. Liu, H. Yang, L. Li, and L. Xing, "Effect of shenyi capsule combined with chemotherapy on advanced non-small cell lung cancer," Jilin Medical Journal, vol. 30, no. 19, pp. 2319-2320, 2009.

[30] P. Lu, W. Su, Z. Miao, H.-R. Niu, J. Liu, and Q.-L. Hua, "Effect and mechanism of ginsenoside Rg3 on postoperative life span of patients with non-small cell lung cancer," Chinese Journal of Integrative Medicine, vol. 14, no. 1, pp. 33-36, 2008.

[31] Y. Liu and S. Liu, "Clinical observation of Shenyi capsule adjuvant chemotherapy for advanced non-small cell lung cancer," Shanxi Medical Journal, vol. 36, no. 6, pp. 554-556, 2007.

[32] S. Liu, L. Sun, L. Ban, and T. Zhou, "Ginsenoside Rg3 capsules combined NP regimen in the treatment of advanced nonsmall cell lung cancer," Chinese Clinical Oncology, vol. 12, no. 11, pp. 847-849, 2007.

[33] Y. Sun, H. Lin, Y. Zhu et al., "A randomized, prospective, multi-centre clinical trial of NP regimen (vinorelbine + cisplatin) plus Gensing Rg3 in the treatment of advanced non-small cell lung cancer patients," Chinese Journal of Lung Cancer, vol. 9, no. 3, pp. 254-258, 2006.

[34] M. Shi, J. Feng, L. Pan, and Z. Zhou, "Clinical observation of Shenyi capsule adjuvant chemotherapy for advanced nonsmall cell lung cancer," Chinese Clinical Oncology, vol. 9, no. 3, pp. 254-258, 2006

[35] H. Lin, B. Piao, and S. Li, "Summary of Shenyi Capsules for the treatment of lung cancer," Chinese Journal of Clinical Oncology, vol. 4, pp. 52-55, 2002.

[36] Z. Chen, C. M. Fillmore, P. S. Hammerman, C. F. Kim, and K.-K. Wong, "Non-small-cell lung cancers: a heterogeneous set of diseases," Nature Reviews Cancer, vol. 14, no. 8, pp. 535-546, 2014

[37] B. C. Bade and C. S. Dela Cruz, "Lung cancer 2020," Clinics in Chest Medicine, vol. 41, no. 1, pp. 1-24, 2020.

[38] J. S. Donington, Y. T. Kim, B. Tong et al., "Progress in the management of early-stage non-small cell lung cancer in 2017," Journal of Thoracic Oncology, vol. 13, no. 6, pp. 767-778, 2018.

[39] X. Ma, R.-S. Li, J. Wang et al., "The therapeutic efficacy and safety of compound kushen injection combined with transarterial chemoembolization in unresectable hepatocellular carcinoma: an update systematic review and meta-analysis," Frontiers in Pharmacology, vol. 7, p. 70, 2016.

[40] W. Guo, H.-Y. Tan, F. Chen, N. Wang, and Y. Feng, "Targeting cancer metabolism to resensitize chemotherapy: potential development of cancer chemosensitizers from traditional Chinese medicines," Cancers, vol. 12, no. 2, 2020.

[41] A. S. T. Wong, C.-M. Che, and K.-W. Leung, "Recent advances in ginseng as cancer therapeutics: a functional and mechanistic overview," Natural Product Reports, vol. 32, no. 2, pp. 256-272, 2015. 